\title{
PRZYMIOTNIKI ODRZECZOWNIKOWE Z SUFIKSEM -NY I -НЫЙ / -EH W J. POLSKIM, ROSYJSKIM, MACEDOŃSKIM
}

\author{
Denominal Adjectives with Suffixes -ny /-ный / -ен in Polish, Russian \\ and Macedonian
}

Keywords: adjectives, word-formation, confrontative analysis, denominal adjectives, derivation

Contact: Uniwersytet Wrocławski; maria.stryszewska@uwr.edu.pl

Przedmiotem niniejszego artykułu jest analiza i opis konfrontatywny denominalnych derywatów z sufiksami $-n y \mathrm{w}$ polskim, -нbiŭ $\mathrm{w}$ rosyjskim oraz $-e H \mathrm{w}$ macedońskim, a także ich rozszerzonych wariantów. Przymiotniki z tym sufiksem w każdym z trzech języków tworzą klasy liczne i stale pomnażane. Ponadto są one niewyspecjalizowane semantycznie, dlatego derywaty z tymi sufiksami nie tworzą typów słowotwórczych, a ich znaczenie może być doprecyzowane jedynie w kontekście rzeczownikowym. Celem pracy jest opis synchroniczno-konfrontatywny opis słowotwórstwa przymiotników odrzeczownikowych tej konkretnej klasy derywatów. Słowotwórstwo tej części mowy zajmuje ważne miejsce w językoznawstwie słowiańskim, ponieważ większość przymiotników to wyrazy motywowane (Dokulil 1979: 31, Satkiewicz 1969: 128). Analiza powinna dać odpowiedź na pytanie jakie są główne różniece między trzema badanymi językami z puntu widzenia użycia formantu -ny/-ныı̆/-eн.

Podstawę materiałową moich badań stanowią słowniki ogólne opisywanych języków: Uniwersalny słownik języka polskiego pod red. S. Dubisza (USJP), Большой толковый словарь русского языка pod red. S. A. Kuznecova (БТСРЯ) oraz sześciotomowy Толковен речник на македонскиот јазик pod red. K. Koneskiego (TPMJ). Aby wyniki badań ilościowych, w tym dane liczbowe dotyczące liczebności derywatów z poszczególnymi formantami i produktywności poszczególnych klas derywatów były możliwie najbardziej precyzyjne należy poddać analizie maksymalnie dużą liczbę formacji. Analizie zostały poddane 10853 derywaty w j. polskim, 10537 w rosyjskim oraz 4695 w macedońskim. Produktywność poszczególnych klas przymiotników odrzeczownikowych przedstawia się następująco: 
j. polski: -owy (41\%), -ny (29,5\%), -ski (19\%), pozostałe formanty (10,5\%), j. rosyjski: -ный (44\%), -ский (31\%), -овый (18\%), pozostałe formanty (7\%), j. macedoński: -ски (52\%), -ен (32\%), -ов (5,5\%), pozostałe formanty (10,5\%).

Wszystkie derywaty zostały opisane z uwzględnieniem następujących parametrów:

1) charakterystyka morfologiczna rzeczownika podstawy,

2) charakterystyka morfonologiczna derywatów,

3) znaczenia kontekstowe derywatów.

\section{Charakterystyka derywatów z formantem -ny / -ен / -ный}

\subsection{Derywaty $\mathrm{z}$ formantem - $n y \mathrm{w} \mathrm{j}$. polskim}

$\mathrm{W}$ materiale j. polskiego znalazły się 3164 derywaty zawierające sufiks $-n y$. Prawie połowę (1575) stanowią przymiotniki z sufiksem prostym. Wśród produktywnych wariantów można wymienić formanty rozszerzone -iczny/-yczny (988), -istyczny/ystyczny (267), -alny (201), -iwny/-ywny (32), -arny (23), -onalny (16), -atyczny (14), owny (13), -astyczny (7). Pozostałe formanty zawierające sufiks -ny występują nielicznie (łącznie tworzą 19 derywatów).

$\mathrm{W}$ języku polskim przymiotniki $\mathrm{z}$ inwariantnym sufiksem -ny tworzone są głównie od podstaw oznaczających rzeczowniki abstrakcyjne ( $80 \%$ całego zbioru). Podstawy słowotwórcze należą do wszystkich rodzajów gramatycznych: żeńskiego (66\%), męskiego (29\%), nijakiego (4,5\%) oraz do liczby mnogiej $(0,5 \%)$.

Sufiks -ny, mimo że charakteryzuje się wysoką produktywnością rzadko bezpośrednio łączy się z podstawą słowotwórczą, stąd warianty rozszerzone oraz szereg alternacji. Tego typu derywacji regularnie towarzyszą ucięcia podstaw: akcesoryjny $\leftarrow$ akcesori-um, eurocentryczny $\leftarrow$ eurocentr-yzm, itd. Zmiękczeniu ulegają spółgłoski $k$, $g, x:$ fizyczny $\leftarrow$ fizyka $(\mathrm{k}: \breve{c})$, śnieżny $\leftarrow$ śnieg $(\mathrm{g}: \check{\text { z }})$, brzuszny $\leftarrow$ brzuch $(\mathrm{x}: \breve{s})$. Pozostałe wymiany spółgłoskowe: wietrzny $\leftarrow$ wiatr $(\mathrm{r}: z ̌)$, finalny $\leftarrow$ finat $(\mathrm{l}: 1)$, uliczny $\leftarrow$ ulica (c:č) a także szereg depalatalizacji. Do najczęstszych alternacji samogłoskowych należą: $k w i e t n y \leftarrow k w i a t$ (a:e), żotędny $\leftarrow \dot{z}$ otądź (ą:ę), jajeczny $\leftarrow$ jajko (\#:e) oraz regularna wokalizacja i/y: eksmisyjny $\leftarrow$ eksmisja, kolonijny $\leftarrow$ kolonia (\#:i/y). 


\subsection{Derywaty $\mathrm{z}$ formantem -ный $\mathrm{w} \mathrm{j}$. rosyjskim}

W materiale języka rosyjskiego derywaty na -ный są reprezentowane najliczniej i tworzą 4719 formacji, co czyni dany sufiks głównym wykładnikiem derywacji przymiotników odrzeczownikowych. Zdecydowana większość przymiotników utworzona jest przy pomocy prostego sufiksu -ныій (3896), natomiast pozostałe 823 derywaty tworzy 35 różnych wariantów rozszerzonych. Do produktywnych sufiksów należy zaliczyć: -онный (292), -альный (99), -ичныій (88), -енный (83), -ивный (66), -тельный (37), -арный (25), -очный (22), -истичный (18), -озный (15). Pozostałe sufiksy występują w pojedynczych derywatach. Większość podstaw słowotwórczych należy do rzeczowników abstrakcyjnych (54\%), choć ich przewaga nad konkretnymi nie jest znaczna (46\%). Podstawy są rodzaju męskiego (51 \%), żeńskiego (42\%), nijakiego (6\%) oraz występują w formie liczby mnogiej (1\%).

Dużo częściej niż w przypadku j. polskiego sufiks łączy się bezpośrednio z podstawą słowotwórczą - tylko u jednej trzeciej analizowanych przymiotników zachodzą alternacje. Także $\mathrm{w}$ j. rosyjskim charakterystyczne są ucięcia podstawy: аллювиальный $\leftarrow$ аллюв-ий, подсолнечный $\leftarrow$ подсолнеч-ник. Wśród wymian spółgłoskowych najczęstsze są palatalizacje, w tym spółgłosek $k, g, x$ : аптечный $\leftarrow$

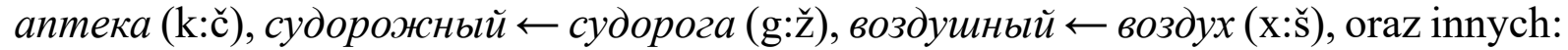
портальный $\leftarrow$ портал (1:1'), ножничный $\leftarrow$ ножницы (с:с̌), a także depalatalizacje spółgłosek wygłosowych. Regularnie zachodzą następujące alternacje wokaliczne: окрасочный $\leftarrow$ окраска (\#:о), петельный $\leftarrow$ петля (\#:e), pozostałe, np.: озерный $\leftarrow$ озеро (e:o) są nieliczne.

\subsection{Derywaty $\mathrm{z}$ formantem -eH $\mathrm{w} \mathrm{j}$. macedońskim}

Przymotników z formantami zawierającymi sufiks -eн wynotowałam 1518 co stanowi 32 \% ogółu. Podobnie jak w wyżej opisanych językach, więszość z nich (1050) zawiera sufiks prosty -ен. Tego typu derywację w j. macedońskim, podobnie jak w j. rosyjskim, cechuje szeroki inwentarz formantów rozszerzonych, których łącznie jest 35. Do produktywnch typów zaliczymy warianty: -ичен (93), -онен (70), -ален (68), -ивен (59), -овен (36), -озен (16), -арен (13), -атичен (9), -онален (8). Pozostałe sufiksy rozszerzone mają niewielki udział.

Przymiotniki za pomocą formantu - ен tworzone są od podstaw o znaczeniu abstrakcyjnym (56\%) lub konkretnym (44\%). Podstawy słowotwórcze należą do wszystkich rodzajów gramatycznych: męskiego (48\%), żeńskiego (45\%), nijakiego (7\%), a pojedyncze są w liczbie mnogiej. 
Podobnie jak w przypadku j. rosyjskiego, w materiale j. macedońskiego tylko $\mathrm{u}$ jednej trzeciej przebadanych derywatów użycie sufiksu -ny wymusza alternacje. Regularnie zachodzą ucięcia podstaw: бигамен $\leftarrow$ бигам-ија, старен $\leftarrow$ стар-ина itp. Podobnie jak w. j polskim i rosyjskim regularnie zachodzą palatalizacje spółgłosek

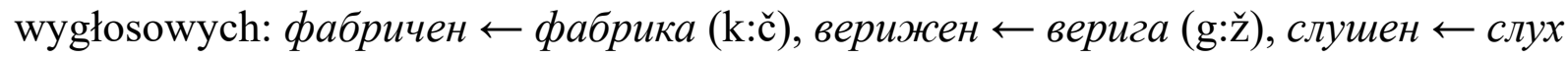
$(\mathrm{x}: \mathrm{s})$, грешен $\leftarrow$ грев (v:š), a także mniej typowe, np.: годишен $\leftarrow$ година (n:š), злакенн $\leftarrow$ злато (t:k'), устен $\leftarrow$ усна (n:t). Wymiany samogłoskowe zachodzą rzadko, charakter regularny ma jedynie oboczność (a:\#): ритмичен $\leftarrow$ ритам, ветрен $\leftarrow$ ветар.

\section{Semantyka derywatów $\mathrm{z}$ formantem -er $\mathrm{w}$ języku macedońskim oraz $-n y$ w języku polskim oraz -ный w języku rosyjskim}

Sufiks -ny jest niewyspecjalizowany funkcjonalnie. Jego znaczenie można doprecyzować jedynie w kontekście rzeczownikowym, w związku z czym osobne miejsce zajmuje analiza znaczeń kontekstowych derywatów, a więc relacji zachodzącej między rzeczownikiem podstawy i rzeczownikiem określanym. Za najwłaściwszy dla celów analizy konfrontatywnej uznaję model opisu derywatów przyjęty w Gramatyce wspótczesnego języka polskiego. Morfologia autorstwa Krystyny Kallas (Kallas 1998: 485-494), na który składają się wspomniane relacje. Podobnie jak w GWJP, wykorzystuję parafrazy grup $\mathbf{A}\left(\mathbf{N}_{\text {podst) }} \mathbf{N}_{\text {okr }}\right.$ (gdzie $\mathbf{N}_{\text {podst }}$ to rzeczownik motywujący, a $\mathbf{N}_{\text {okr }}$ to rzeczownik określany). Analiza znaczeń kontekstowych pozwala na opis znacznie dokładniejszy od przypisywanego derywatom znaczenia ogólnego wyrażonego formułą typu 'odnoszący się do tego, co nazywa rzeczownik podstawy', mianowicie pozwala na wyodrębnienie znaczeń szczegółowych, takich jak np. 'podobny, taki jak to, co nazywa podstawa słowotwórcza', 'zrobiony, wykonany z tego, co nazywa podstawa słowotwórcza' i innych.

\subsection{Użycia subiektowe (SUB)}

Rzeczownik podstawy nazywa subiekt, a rzeczownik określany czynność przy niewyrażonym predykacie: pol. zakażenie bakteryjne - 'zakażenie wywołane przez bakterie', ros. конный номер в цирке (numer konny w cyrku) - 'numer wykonywany przez konia', mac. овошна градина (owocowy ogród) - 'ogród, w którym rosną owoce'. 


\subsection{Użycia obiektowe (OB)}

Podstawa przymiotnika nazywa obiekt, a rzeczownik określany może pełnić inne dowolne funkcje: pol. targ rybny - 'targ, na którym sprzedawane są ryby, targ z rybami', ros. бройлерная фабрика (fabryka brojlerów) - 'fabryka, w której hodowane są brojlery, produkowane jest mięso z brojlerów', mac. колонијална продавница (sklep kolonialny) - 'sklep, w którym sprzedawane są produkty kolonialne'.

\subsection{Użycia dzierżawcze (POSS)}

W tym wypadku podstawa przymiotnika nazywa posiadacza, a rzeczownik określany posiadany przez niego obiekt: pol. dom rodzinny, mac. семејна куќa (dom rodzinny) 'dom, który należy do rodziny', ros. государственная собственность (własność państwowa) - 'własność należąca do państwa'. Derywaty utworzone za pomocą sufiksu -ny/-Hbiŭ/-eн rzadko występują w tym użyciu, ponieważ rzeczowniki motywujące najczęściej należą do nieożywionych.

\subsection{Użycia instrumentowe (INSTR)}

Rzeczownik podstawy nazywa instrument lub ściślej środek czynności, a rzeczownik określany tę czynność lub obiekt przy niewyrażonym predykacie: pol. sygnat dymny 'sygnał wysyłany za pomocą dymu', ros. ножная швейная машина (nożna maszyna do szycia) - 'maszyna do szycia obsługiwana przy pomocy nogi', mac. рачна изработка (robótka ręczna) - 'robótka wykonywana przy użyciu rąk'.

\subsection{Użycia materiałowe (MAT)}

Taka relacja zachodzi, gdy przymiotnik podstawy nazywa materiał, z którego wykonany jest wytwór nazwany przez rzeczownik określany: pol. srebrne kolczyki - 'kolczyki wykonane ze srebra', ros. каменный мост (kamienny most) - 'most zbudowany z kamienia', mac. сатинен фустан (satynowa sukienka) - 'sukienka uszyta z satyny'.

\subsection{Użycie wskazujące na wytwór (RES)}

Odwrotną do poprzedniej relacją jest użycie wskazujące na wytwór, tj. rzeczownik podstawy nazywa wytwór, a rzeczownik określany materiał, z którego jest wykonany, lub materiał przeznaczony do jego wykonania: pol. deski trumienne - 'deski, z których wykonuje się trumny', ros. ниточное cырье (surowiec niciany) - 'surowiec 
przeznaczony do produkcji nici (nitek) ', mac. подни мозаици (mozaika podłogowa) 'mozaika przeznaczona na podłogę'.

\subsection{Użycia genetyczne (GEN)}

Użycia genetyczne wskazują na relację pochodzenia. Rzeczownik określany nazywa przedmiot, który pochodzi od przedmiotu nazwanego przez rzeczownik podstawy: pol. tluszcz roślinny - 'tluszcz wytłoczony z roślin', ros. куриное мясо (kurze mięso) 'mięso pochodzące od kury', mac. ржено брашно (mąka żytnia) - 'mąka uzyskana z żyta'.

\subsection{Użycia syngulatywne (SING)}

Użycia syngulatywne, to użycia wskazujące na element zbioru, warunkiem zachodzenia takiej relacji jest kolektywne znaczenie rzeczownika określanego. Rzeczownik podstawy nazywa element zbioru, rzeczownik określany nazywa zbiór: pol. kótko plastyczne - 'kółko złożone z plastyków, osób zajmujących się plastyką', ros. токарная бригада (brygada tokarska) - 'brygada złożona z tokarzy', mac. редакиионен одбор (zespół redakcyjny) - 'zespół tworzący redakcję'.

\subsection{Użycia wskazujące na calość w relacji do części (TOT)}

Użycia przymiotnika wskazujące na całość, którą nazywa rzeczownik podstawy do części, którą nazywa rzeczownik określany; pol. matżowina uszna - 'małżowina będąca częścią ucha', ros. абрикосная косточка (pestka brzoskwiniowa) - 'pestka, która jest częścią brzoskwini', mac. рачна коска (ręczna kostka) - 'kostka, kość będąca częścią ręki'.

\subsection{Użycia partytywne (PART)}

Użycia partytywne wskazują na relację odwrotną do omówionej wyżej. Rzeczownik podstawy nazywa część, która składa się na całość nazwaną rzeczownikiem określanym: pol. leki hormonalne - 'leki, w których skład wchodzą hormony', ros. клавишный инструмент (instrument klawiszowy) - 'instrument składający się z klawiszy', mас. sвездена галаксија (gwiezdna galaktyka) - 'galaktyka złożona z pojedynczych gwiazd'. 


\subsection{Użycia charakterystyczne konkretne (CHAR-KONKR)}

Użycia charakterystyczno-konkretne często zbieżne są z użyciami partytywnymi, w tym jednak wypadku część, którą nazywa rzeczownik podstawy jest cechą dystynktywną: pol. staw rybny - 'staw, w którym hodowane są ryby', ros. звездное небо, тас. звездено небо (gwiaździste niebo) - 'niebo, które charakteryzuje się dużą ilością gwiazd'.

\subsection{Użycia charakterystyczne abstrakcyjne (CHAR-ABSTR)}

Użycia charakterystyczno-abstrakcyjn to takie, w których rzeczownik podstawy przypisuje cechę abstrakcyjną przedmiotowi lub czynności, którą nazywa rzeczownik określany; warunkiem zachodzenia tej relacji jest abstrakcyjny charakter rzeczownika podstawy: pol. ambitny uсzeń - 'uczeń, którego cechuje ambicja', ros. абсорбционная способность (zdolność absorpcyjna) - 'skłonność do absorpcji', mac. идеална љубов (idealna miłość).

\subsection{Użycia porównawcze (SIMIL)}

Rzeczownik motywujący stanowi podstawę porównania, a rzeczownik określany jest w tej relacji członem porównywanym: pol. aksamitna miękkość - 'miękkość, która (w dotyku) przypomina aksamit', ros. ватные облака (chmury z waty) - 'chmury, które wyglądają jak wata', mac. тркалезен килим (kolisty dywan) - 'dywan kształtem przypominający koło'.

\subsection{Użycia zakresowe (ZAKRES)}

Użycia zakresowe pełnią jedynie funkcję nominalną i zawężają zakres znaczeniowy rzeczownika. Tego typu relację można przedstawić przy pomocy parafrazy: ten rzeczownik określany to ten rzeczownik podstawy i odwrotnie: pol. agresywne zachowanie - 'to zachowanie jest agresją, a agresja jest rodzajem zachowania', ros. крыжсовенный куст (krzew agrestowy) - 'ten krzew to agrest, a agrest jest krzewem', mac. соновна состојба (senny stan) - 'ten stan to sen, a sen jest stanem'.

\subsection{Użycia limitujące (LIMIT)}

Użycia limitujące również zawężają zakres rzeczownika, ale nie odpowiada im wymieniona wcześniej parafraza: pol. błąd logiczny - 'błąd z zakresu logiki', ros. 
махматный турнир (turniej szachowy) - 'turniej w dyscyplinie szachów', mac. научни истражувања (badania naukowe) - 'badania z zakresu nauki'.

\subsection{Użycia lokatywne (LOC)}

Użycia lokatywe mogą mieć dwojaki charakter: miejscowy lub kierukowy. Rzeczownik podstawy jest nazwą miejsca (lub kierunku): pol. polne kwiaty - 'kwiaty rosnące na polu', ros. степные озера (jeziora stepowe) - 'jeziora występujące na obszarze stepów', mac. sиден календар (kalendarz ścienny) - 'kalendarz wiszący na ścianie'.

\subsection{Użycia temporalne (TEMP)}

Rzeczownik podstawy nazywa odcinek czasu, natomiast rzeczownik określany pełni dowolne funkcje: pol. wiosenna kurtka - 'kurtka przeznaczona do noszenia wiosną', ros. ночная темнота (nocna ciemność) - 'ciemność, która ma miejsce w nocy', mac. квартален план (plan kwartalny) - 'plan działań przewidziany na kwartał'.

\subsection{Przymiotniki czynnościowe, procesualne i stanowe (CZYN)}

Ostatnia grupa odnosi się do przymiotników będących nazwami czynności, procesów lub stanów. Często przymiotniki motywowane są odczasownikowymi rzeczownikami: pol. oddziat interwencyjny - 'oddział, który przeprowadza interwencję', ros. родильное отделение (oddział porodowy) - 'oddział, na ktorym odbywają się porody', mac. навигациионе инструмент (przyrząd nawigacyjny) - 'przyrząd służący do nawigacji, nawigujący'.

\section{Wnioski}

Jak pokazuje analiza, sufiks $-n y /-H b u \check{u} /-e H$ w każdym z omówionych języków łączy się z podstawami rzeczownikowymi należącymi do wszystkich rodzajów gramatycznych, o różnej charakterystyce morfonologicznej, o znaczeniu zarówno konkretnym jak i abstrakcyjnym. Prowadzi to do wniosku, że sufiks -ny/-ныцй-eн jest uniwersalnym środkiem słowotwórczym wykorzystywanym w derywacji przymiotników odrzeczownikowych. Widać również tendencję w języku polskim do tworzenia derywatów od rzeczowników abstrakcyjnych rodzaju żeńskiego. Materiał j. rosyjskiego i macedońskiego wykazuje więcej zbieżności, a sam formant i jego warianty mają znacznie szersze zastosowanie. 
Derywaty $\mathrm{w}$ tej grupie wykazują dużo zbieżności, często ekwiwalenty w poszczególnych językach utworzone są za pomocą tego samego sufiksu (por. pol. kolonialny, ręczny, ścienny, ros. колониальный, ручной, стенной, тас. колонијален, рачен, sиден).

Również przeprowadzona analiza semnatyczna znaczeń kontekstowych pokazuje, że w każdym z trzech języków derywaty z formantem -ny/-eн/-ный tworzą wszystkie typy relacji. Ponadto jeden przymiotnik może występować w kilku relacjach i zmieniać znaczenie w zależności od rzeczownika określanego: mac. рачна изработка (robótka ręczna) - 'praca wykonana przy pomocy rąk' - w tym wypadku ręka jest instrumentem (INSTR) lub precyzyjniej - środkiem czynności (Grochowski 1975) oraz: рачна коска (kość ręki) - 'kość będąca częścią ręki' (TOT). W przypadku użyć subiektowych (SUB) „za subiekt uznamy też nazwę przedmiotu lokalizowanego" (GWJP 1998: 485), np. mac. овошна градина (ogród owocowy) - 'ogród, w którym rosną owoce', analogicznie pol. ogród warzywny - 'ogród, w którym rosną warzywa'.

Ponieważ przymiotniki utworzone przy pomocy sufiksu -ny tworzą wszystkie z opisanych relacji semantycznych we wszystkich trzech językach, sufiks ten, mimo wielu ograniczeń natury morfonologicznej, można uznać za najbardziej uniwersalny dla słowotwórstwa przymiotnika w językach słowiańskich (Stryszewska 2020).

\section{Summary}

In this article have been presented denominal adjectives with suffix -ny / -ный / -ен in Polish, Russian and Macedonian languages. This formative along with suffixes -owy / -овыци / -ов, -ски / -ский / -ski and paradigmatic formative (inflection) is one of the main indicators of denominal adjectives' word-formation in the abovementioned languages, moreover the common feature of all of these formatives is the fact that they are not functionally specialised which means that adjectives formed with their use do not have determinate meaning outside contextual use.

\section{Literatura}

Dokulil, M. Teoria derywacji. Tłum. Bluszcz, A., Stachowski, J. Wrocław: Ossolineum, 1979.

Kallas, K. Przymiotnik. In: Grzegorczykowa, R., Laskowski, R., Wróbel, H. (eds.) Gramatyka wspótczesnego języka polskiego. Morfologia. Warszawa: PWN, 1998. 
Kowalik, K. Budowa morfologiczna przymiotnikow polskich. Wrocław: Ossolineum, 1977.

Urban, M. Wspótczesne przymiotniki odrzeczownikowe z wybranymi formantami sufiksalnymi. Toruń: Wydawnictwo UMK, 2006.

Grochowski, M. Środek czynności w strukturze zdania. Narzędzie, substancja, materiał. In: Prace Instytutu Języka Polskiego PAN. Wrocław: Ossolineum, 1975.

Stryszewska M. Niektóre właściwości przymiotników odrzeczownikowych z sufiksem -owy/-oвblŭ/-oв w językach polskim, rosyjskim i macedońskim. In: Dombrowski, A., Rudnicka, M., Żarski, W. (eds.) Pojęcie-kategoria-stowo w teorii i praktyce. Kraków: Impuls, 2019, s. 165-176.

Satkiewicz, H. Produktywne typy stowotwórcze wspótczesnego języka polskiego. Warszawa: Wydawnictwa Uniwersytetu Warszawskiego, 1969.

\section{Słowniki}

USJP - Uniwersalny stownik języka polskiego. Dubisz, S. (ed.) Warszawa: Wydawnictwo Naukowe PWN, 2003.

БТСРЯ - Большой толковый словарь русского языка. Кузнецов, С. А. (еd.) СанктПетербург: Норинт, 2008.

ТРМЈ - Толковен речник на македонскиот јазик. T. 1-6. Конески, К. (ed.) Скопје: ИМЈ, 2005-2011. 